\title{
Linking certain physical characteristics with postharvest needle abscission resistance in balsam fir
}

\author{
M.T. MacDonald, R.R. Lada* and R.S. Veitch \\ Christmas Tree Research Center, Dalhousie Agricultural Campus, Bible Hill, Nova Scotia, Canada, B2N 5E3. \\ *E-mail: raj.lada@dal.ca
}

\begin{abstract}
Balsam fir trees are the most popular choice for Christmas trees in Atlantic Canada and a major export commodity, despite postharvest needle abscission challenging the industry's viability. The objective of this study was to determine if any needle or branch biophysical and/or morphological characteristics may be linked with needle abscission resistance (NAR) in balsam fir. A total of 17 different parameters were measured in branches of clones that belonged to low, medium, or high needle abscission resistant groups. Of the parameters measured, branch diameter, initial mass, needle density, break strength, and needle retention duration were significantly $(P$ $<0.05$ ) different between genotype groups. It was found that high NAR genotypes had a 9.1\% smaller diameter, $25.0 \%$ lower initial mass, 33.2\% lower needle break strength, 32.4\% lower needle density, and 91\% longer needle retention than low NAR clones. Of these factors, needle density was the best predictor for needle retention duration $\left(R^{2}=47 \%\right)$. Identification of these parameters is an important first step to understand physiological and genetic linkage for development of Christmas trees with high NAR.
\end{abstract}

Key words: Abiesbalsamea, break strength,Christmas tree, conifer, needle density, needle retention, senescence, xylem pressure potential

\section{Introduction}

Balsam fir is the most popular Christmas tree species used in Atlantic Canada, with over 3 million trees harvested each year contributing approximately $\$ 72$ million to the economy (MacDonald, 2010). However, postharvest needle abscission poses a major problem and may result in low consumer satisfaction and a shift in preference towards artificial trees. In order to help solve postharvest abscission problems, several recent studies have focused on identifying and understanding key factors linked with abscission.

There is considerable variation in needle retention characteristics between balsam fir genotypes. Four separate screening experiments of over 100 unique genotypes identified that complete abscission occurs between 6 and 60 days after harvest (MacDonald and Lada, 2008; MacDonald et al., 2012, unpublished results). Though variation in abscission is high between balsam fir genotypes, variation is relatively small within the same genotype tested in successive years. As a result, genotypes have been classified according to their needle abscission resistance (NAR), which is the length of time a branch resists abscission after harvest. Three broad classifications have been established: low NAR (abscission $<20$ days), moderate NAR (abscission between 21 and 40 days), and high NAR (abscission > 41 days) MacDonald (2010). A comparison between NAR classes allows for identification of key characteristics related to abscission. For example, ethylene was recently identified as a signal molecule for postharvest abscission in balsam fir (MacDonald et al., 2010; 2011). Comparison of ethylene evolution and sensitivity in balsam fir of low and high NAR determined that low NAR trees release ethylene at a $50 \%$ higher rate and are more sensitive to low (i.e. $<10 \mathrm{ppm}$ ) concentrations of ethylene (MacDonald et al., 2012).
Most of the research to date has focused on physiological mechanisms, such as changes in ethylene or abscisic acid, or abscission mitigating technologies such as cold acclimation, ethylene inhibition, and light emitting diodes (MacDonald et al., 2010b; Thiagarajan et al., 2012; Veitch et al., 2012). There is little information available regarding biophysical and morphological characteristics that may be linked to NAR. MacDonald (2010) tested a theory among producers that trees with short needle lengths retain needles longer, but found no significant relationship between needle length and NAR. However, this result does not preclude the possibility of other physical factors that may be better indicators of NAR. Identification of these factors is of practical use as a method to choose trees with superior needle retention for purchase or breeding, and is of scientific relevance as it could also raise questions as to why certain factors are linked to postharvest needle abscission. Thus, the objective of this study was to identify any differences in biophysical and morphological characteristics of low, moderate, or high NAR genotypes and potentially link those characteristics to the length of time until complete postharvest abscission.

\section{Materials and methods}

Experimental design: A total of 45 branches, cut from the most recent 2 years of growth at $1.5 \mathrm{~m}$ above ground, were collected from a balsam fir clonal orchard at the Tree Breeding Centre, Department of Natural Resources, Debert, NS (45 $25^{\circ}$ $\mathrm{N}, 63^{\circ} 28^{\prime} \mathrm{W}$ ) on July 13, 2010. The experiment followed a completely randomized design. NAR classification was used as the explanatory variable at 3 levels: low, moderate, and high. Fifteen branches were randomly selected from each NAR class and each branch served as a replicate. Handling and storage of branches was meant to simulate conventional industry procedures 
for tree harvest. Thus, branches were not provided any water and were stored at $20^{\circ} \mathrm{C}$ for 16 hours during the day, then $15^{\circ} \mathrm{C}$ for 8 hours at night. A relatively low light intensity of $80 \mu \mathrm{mol} \mathrm{m} \mathrm{m}^{-2} \mathrm{~s}^{-1}$ was provided constantly throughout the experiment simulating household or covered storage conditions.

Branch related response variables: Response variables directly related to branch included diameter, length, mass, internode distance, fragrance, flushing, and xylem pressure potential (XPP). Branch diameter was measured at the cut end and length was determined as the distance from the cut end to the end of the primary branch. Branch mass was measured once immediately after sample collection (initial mass) and again after complete abscission (final mass). Internode distance was the average distance between each node of first and second year growth. Flushing was a count of new growth areas on the branch. Fragrance was determined by smelling a branch and comparing it to needle extracts on a scale of 0 to 5 . A value of zero was assigned to water control and values $1,2,3,4$, and 5 corresponded needle extract concentrations of 2.5, 5, 7.5, 10, and $12.5 \mathrm{ppm}$, respectively. Finally, XPP was determined using a pressure bomb and recording the pressure required to force water out of the xylem. XPP was determined immediately after harvest $\left(\mathrm{XPP}_{0}\right)$, after complete abscission $\left(\mathrm{XPP}_{\mathrm{f}}\right)$, and then calculated as the difference between initial and final values $\left(\triangle \mathrm{XPP}=\mathrm{XPP}_{\mathrm{f}}\right.$ $\left.-\mathrm{XPP}_{0}\right)$.

Needle related response variables: Response variables directly related to the needles included needle retention duration (NRD), angle of attachment, needle proportion, needle density, needle length, relative water content, and break strength. NAR was determined as the number of days required to complete abscission. Angle of attachment was the average angle of needles from three positions along the primary branch, assuming that the direction of the cut end was $0^{\circ}$. Needle proportion was the weight of shed needles as a percentage of total branch fresh mass. Needle density was the average number of needles in a $1 \mathrm{~cm}$ length averaged from three positions along the primary branch. Needle length was the average length of 5 randomly selected needles. Relative water content was calculated from measurements of dry needle mass, fresh needle mass, and turgid needle mass according to the formula (fresh needle mass - dry needle mass) / (turgid needle mass-dry needle mass) x100. Finally, break strength was determined as the force required to remove a needle from the branch. A clip, which was attached to electronic spring scale, was fastened to a needle. The branch was pulled away from the spring scale and force was recorded using Logger Pro 3.1 (Vernier Software and Technology, Beaverton, OR), which allows force to be plotted against time. The amount of force required to remove a needle is represented as a peak on the force-time graph.

Statistical analysis: Data were subjected to an analysis of variance using SAS v9.1 to determine significant differences ( $\alpha$ $=0.05$ ) in characteristics of low, moderate, and high NAR balsam fir. Statistical assumptions of normality, constant variance, and independence were valid in all parameters except break strength. Break strength required a square root transformation to induce constant variance and normality. When statistical significance was detected, multiple means comparison was conducted with least significant difference (LSD).

\section{Results}

Of the 17 physical characteristics measured, only 5 were found to be significantly different between different NAR genotypes. The two branch characteristics linked to NAR were branch diameter and initial mass (Table 1). High NAR branches had a 9.1\% smaller diameter and $25.0 \%$ lower initial mass than low NAR branches. The three needle characteristics linked to NAR were break strength, needle density, and NRD (Table 2). High NAR branches had a 33.2\% lower break strength, 32.4\% lower needle density, and $91.3 \%$ higher NRD than low NAR branches.

Table 1. Branch characteristics of low, moderate, and high needle abscission resistant balsam fir genotypes. An asterisks indicates that a characteristic was significant at $\alpha=0.05$ and letter groupings were determined using least significant difference multiple means comparison. Means for each NAR classification were calculated from 15 replicates.

\begin{tabular}{lccc}
\hline Physical & \multicolumn{3}{c}{ NAR Classification } \\
\cline { 2 - 4 } Characteristic & Low & Moderate & High \\
\hline Branch diameter $(\mathrm{mm})^{*}$ & $6.53^{\mathrm{a}}$ & $6.02^{\mathrm{b}}$ & $5.94^{\mathrm{b}}$ \\
Branch length $(\mathrm{cm})$ & 32.00 & 33.10 & 31.0 \\
Initial mass $(\mathrm{g})^{*}$ & $29.38^{\mathrm{a}}$ & $27.47^{\mathrm{a}}$ & $22.04^{\mathrm{b}}$ \\
Final mass $(\mathrm{g})$ & 5.86 & 5.55 & 5.14 \\
Internode distance $(\mathrm{cm})$ & 10.60 & 10.5 & 9.9 \\
Fragrance & 3.00 & 3.0 & 2.0 \\
Flushing & 9.00 & 10.0 & 8.0 \\
XPP $_{0}$ & -0.76 & -0.66 & -0.59 \\
XPP $_{\mathrm{f}}$ & -0.77 & -0.58 & -0.50 \\
XXPP & -0.01 & 0.08 & 0.09 \\
\hline
\end{tabular}

Table 2. Needle characteristics of low, moderate, and high needle abscission resistant balsam fir genotypes. An asterisks indicates that a characteristic was significant at $\alpha=0.05$ and letter groupings were determined using least significant difference multiple means comparison. Means for each NAR classification were calculated from 15 replicates.

\begin{tabular}{|c|c|c|c|}
\hline \multirow{2}{*}{$\begin{array}{l}\text { Physical } \\
\text { Characteristic }\end{array}$} & \multicolumn{3}{|c|}{ NAR Classification } \\
\hline & Low & Moderate & High \\
\hline Break strength $(\mathrm{N})^{*}$ & $1.87^{\mathrm{a}}$ & $1.61^{\mathrm{ab}}$ & $1.25^{\mathrm{b}}$ \\
\hline RWC (\%) & 81.1 & 85.5 & 83.9 \\
\hline Density (needles/cm)* & $34.0^{\mathrm{a}}$ & $28.0^{\mathrm{b}}$ & $23.0^{\mathrm{c}}$ \\
\hline Needle length (mm) & 15.42 & 14.71 & 15.95 \\
\hline Needle proportion $(\%)^{*}$ & 80.1 & 79.8 & 76.6 \\
\hline Angle of attachment $\left(^{\circ}\right)$ & 102.0 & 104.0 & 107.0 \\
\hline NRD (days)* & $15.0^{\mathrm{c}}$ & $21.2^{\mathrm{b}}$ & $28.7^{\mathrm{a}}$ \\
\hline
\end{tabular}

Plotting all biophysical and morphological parameters against NRD revealed several weak relationships $\left(R^{2}<10 \%\right)$. However, there was a significant negative relationship $(P=0.003)$ between needle density and NRD, which suggests a higher needle density may result in poorer needle retention (Fig. 1).

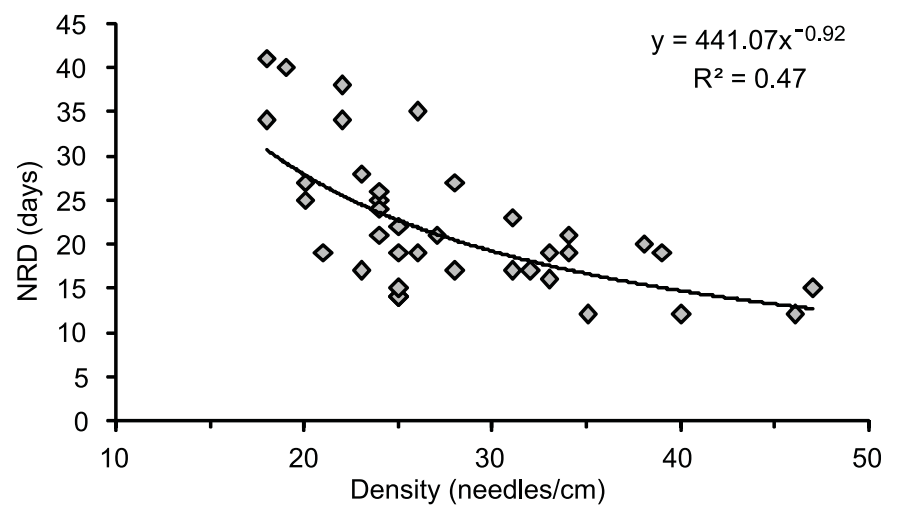

Fig.1. Negative relationship between needle density (x-axis) and time required for complete abscission (y-axis). The relationship is best described with $\mathrm{NRD}=441$ (Density $^{-0.9} . \mathrm{N}=45$. 


\section{Discussion}

The link between NAR and NRD was expected, since NAR classifications were based on NRD screenings. Previous average NRDs for low, moderate, and high NAR classes were 14.9, 32.1, and 47.3 days, respectively (MacDonald and Lada, 2008; MacDonald, 2010). The NRD values determined from this experiment were similar for the low NAR genotypes, but much lower for moderate and high NAR genotypes. The likely cause for this discrepancy may be the collection date as branches were collected in July for this experiment as compared to October for previous work and it has been suggested that a period of cold acclimation beginning in autumn increases needle retention in conifers (MacDonald and Lada, 2008; Mitcham-Butler, 1988; Thiagarajan, 2012; Thiagarajan et al., 2012).

Branch diameter, mass, and needle density were significantly lower in high NAR branches compared to low NAR branches. It is possible that each of these characteristics is linked to decreased water use, which has long been suggested as a key trigger for postharvest needle loss in conifers (Chastagner and Riley, 2003). However, final XPP values of approximately -0.5 to $-0.8 \mathrm{MPa}$ were much higher (more positive) than threshold values of -3 to $-4 \mathrm{MPa}$ found in related species (Chastagner and Riley, 2003; Mitcham-Butler et al., 1988). Also, there was no significant decline in XPP over the duration of the experiment. The XPP observations in this experiment were consistent with the hypothesis that postharvest needle abscission in balsam fir must be due to a factor other than declining water status (MacDonald, 2010). The exact reason that diameter, mass, and needle density may be linked to NAR is not known. It is possible that lower needle density may have reduced water loss, thereby delaying postharvest needle abscission. If this is so, XPP would have declined significantly in low NAR genotypes, but a lack of a significant relationship between XPP and NAR suggests a weak link between postharvest dehydration and NAR.

The other parameter linked with NAR was break strength, although the relationship was rather counterintuitive. A decrease in break strength is normally associated with accelerated abscission (Brummell et al., 1999). In our experiment, however, high break strength was consistently associated with low NAR genotypes. It's obvious from the early abscission of low NAR genotypes that break strength must rapidly decrease after harvest, but there is currently no explanation for high initial break strengths compared to high NAR genotypes.
Overall, increased needle retention was observed in branches with a lower stem diameter, mass, break strength, and needle density. These results identify several factors not previously known to be associated with postharvest abscission in balsam fir and also offer a potential screening tool to producers, who may selectively breed trees with the aforementioned characteristics. In addition, if consumers are made aware of these characteristics it will allow for more informed Christmas tree selection.

\section{References}

Brummell, D.A., B.D. Hall and A.B. Bennett, 1999. Antisense suppression of tomato endo-1,4- $\beta$-glucanase Cel 2 mRNA increases the force required to break fruit abscission zones but does not affect fruit softening. Plant Mol. Biol., 40: 615-622.

Chastagner, G.A. and K.L. Riley, 2003. Postharvest quality of noble and Nordmann fir Christmas trees. HortScience, 38: 419-421.

MacDonald, M.T. 2010. Physiological Significance of Ethylene in Needle Abscission of Root-detached Balsam Fir (Abiesbalsamea L.). Ph.D.Diss., Université Laval, 2010. 161 pp.

MacDonald, M.T. and R.R. Lada, 2008. Cold acclimation can benefit only the clones with poor needle retention duration (NRD) in balsam fir. HortScience, 43: 1273.

MacDonald, M.T., R.R. Lada, M. Dorais, S. Pepin, Y. Desjardins and A.I. Martynenko, 2011. Ethylene exposure duration affects postharvest needle abscission in balsam fir (Abiesbalsamea L.). HortScience, 46: 260-264.

MacDonald, M.T., R.R. Lada, A.I. Martynenko, M. Dorais, S. Pepin and Y. Desjardins, 2010. Ethylene triggers needle abscission in root-detached balsam fir. Trees, 24: 879-886.

MacDonald, M.T., R.R. Lada, A.I. Martynenko, M. Dorais, S. Pepin and Y. Desjardins, 2012. Is there a relationship between ethylene evolution, ethylene sensitivity, and needle abscission in root-detached balsam fir? Acta Hort., 932: 405-412.

Mitcham-Butler, E.J., L.E. Hinesley and D.M. Pharr, 1988. Effect of harvest date, storage temperature, and moisture status on postharvest needle retention of Fraser fir. J. Environ. Hort., 6: 1-4.

Thiagarajan, A. 2012. Physiology of Low Temperature-modulated Postharvest Needle Senescence and Abscission in Balsam Fir (Abiesbalsamea L.). Ph.D. Diss., Université Laval, 2012. 159 pp.

Thiagarajan, A., R. Lada, S. Pepin, S.F. Forney, Y. Desjardins and M. Dorais, 2012. Characterization of phytohormonal and postharvest senescence responses of balsam fir (Abiesbalsamea (L.) Mill.) exposed to short-term low temperature. Trees, 26: 1545-1553.

Veitch, R.S., R.R. Lada and M.T. MacDonald, 2012. Effect of light emitting diodes (LEDs) on postharvest needle retention in balsam fir (Abiesbalsamea L.). J. Appl. Hort., 14: 13-17. 